NASA/TM-2002-211814
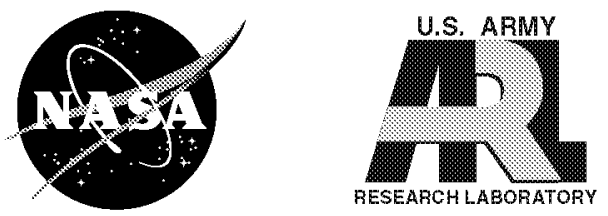

\title{
Spiral Bevel Gear Damage Detection Using Decision Fusion Analysis
}

Paula J. Dempsey

Glenn Research Center, Cleveland, Ohio

Robert F. Handschuh

U.S. Army Research Laboratory, Glenn Research Center, Cleveland, Ohio

Abdollah A. Afjeh

University of Toledo, Toledo, Ohio 
The NASA STI Program Office ... in Profile

Since its founding, NASA has been dedicated to the advancement of aeronautics and space science. The NASA Scientific and Technical Information (STI) Program Office plays a key part in helping NASA maintain this important role.

The NASA STI Program Office is operated by Langley Research Center, the Lead Center for NASA's scientific and technical information. The NASA STI Program Office provides access to the NASA STI Database, the largest collection of aeronautical and space science STI in the world. The Program Office is also NASA's institutional mechanism for disseminating the results of its research and development activities. These results are published by NASA in the NASA STI Report Series, which includes the following report types:

- TECHNICAL PUBLICATION. Reports of completed research or a major significant phase of research that present the results of NASA programs and include extensive data or theoretical analysis. Includes compilations of significant scientific and technical data and information deemed to be of continuing reference value. NASA's counterpart of peerreviewed formal professional papers but has less stringent limitations on manuscript length and extent of graphic presentations.

- TECHNICAL MEMORANDUM. Scientific and technical findings that are preliminary or of specialized interest, e.g., quick release reports, working papers, and bibliographies that contain minimal annotation. Does not contain extensive analysis.

- CONTRACTOR REPORT. Scientific and technical findings by NASA-sponsored contractors and grantees.
- CONFERENCE PUBLICATION. Collected papers from scientific and technical conferences, symposia, seminars, or other meetings sponsored or cosponsored by NASA.

- SPECIAL PUBLICATION. Scientific, technical, or historical information from NASA programs, projects, and missions, often concerned with subjects having substantial public interest.

- TECHNICAL TRANSLATION. Englishlanguage translations of foreign scientific and technical material pertinent to NASA's mission.

Specialized services that complement the STI Program Office's diverse offerings include creating custom thesauri, building customized data bases, organizing and publishing research results... even providing videos.

For more information about the NASA STI Program Office, see the following:

- Access the NASA STI Program Home Page at http://wwo.sti.nasa.gov

- E-mail your question via the Internet to help@stinasa.gov

- Fax your question to the NASA Access Help Desk at 301-621-0134

- Telephone the NASA Access Help Desk at 301-621-0390

- Write to: NASA Access Help Desk NASA Center for AeroSpace Information 7121 Standard Drive Hanover, MD 21076 
NASA/TM-2002-211814
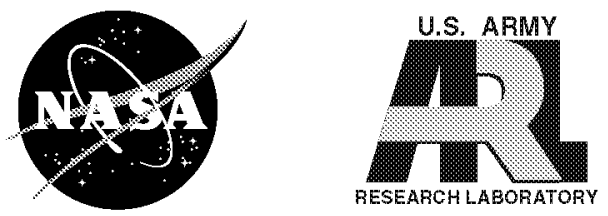

\section{Spiral Bevel Gear Damage Detection Using Decision Fusion Analysis}

Paula J. Dempsey

Glenn Research Center, Cleveland, Ohio

Robert F. Handschuh

U.S. Army Research Laboratory, Cleveland, Ohio

Abdollah A. Afjeh

University of Toledo, Toledo, Ohio

Prepared for the

Fifth International Conference on Information Fusion

sponsored by the International Society of Information Fusion

Annapolis, Maryland, July 8-11, 2002

National Aeronautics and

Space Administration

Glenn Research Center 
Available from

NASA Center for Aerospace Information 7121 Standard Drive

Hanover, MD 21076
National Technical Information Service 5285 Port Royal Road Springfield, VA 22100

Available electronically at http://glrs.grcnasa.gov 


\title{
Spiral Bevel Gear Damage Detection Using Decision Fusion Analysis
}

\author{
Paula J. Dempsey \\ National Aeronautics and Space Administration \\ Glenn Research Center \\ Cleveland, Ohio 44135 \\ E-mail: paula.j.dempsey@grc.nasa.gov \\ Robert F. Handschuh \\ U.S. Army Research Laboratory \\ Glenn Research Center \\ Cleveland, Ohio 44135 \\ E-mail: robert.f. handschuh@grc.nasa.gov \\ Abdollah A. Afjeh \\ The University of Toledo \\ Toledo, Ohio 43606 \\ E-mail: AAfjeh@UTNet.UToledo.Edu
}

\begin{abstract}
A diagnostic tool for detecting damage to spiral bevel gears was developed. Two different monitoring technologies, oil debris analysis and vibration, were integrated using data fusion into a health monitoring system for detecting surface fatigue pitting damage on gears. This integrated system showed improved detection and decision-making capabilities as compared to using individual monitoring technologies. This diagnostic tool was evaluated by collecting vibration and oil debris data from fatigue tests performed in the NASA Glenn Spiral Bevel Gear Fatigue Rigs. Data was collected during experiments performed in this test rig when pitting damage occurred. Results show that combining the vibration and oil debris measurement technologies improves the detection of pitting damage on spiral bevel gears.
\end{abstract}

\section{Introduction}

Helicopter transmission integrity is important to helicopter safety because helicopters depend on the power train for propulsion, lift, and flight maneuvering. In order to detect impending transmission failures, the ideal diagnostic tools used in the health monitoring system would provide realtime health monitoring of the transmission and would demonstrate a high level of reliable detection to minimize false alarms. Today's helicopter health monitoring systems (HUMS) are not yet capable of real-time, on-line, health monitoring. Current data collected by HUMS is processed after the flight, and the health status reported is often plagued with high false alarm rates and undetected faults. The current fault detection rate of commercially available HUMS through vibration analysis is 70 percent [1]. False warning rates average 1 per hundred flight hours [2]. Often these systems are complex and require extensive interpretation by trained diagnosticians [3].

The objective of this research is to integrate oil debris and vibration based gear damage detection techniques into a health monitoring system capable of detecting gear pitting damage with improved detection and decisionmaking capabilities as compared to existing individual diagnostic tools. This hypothesis will be evaluated experimentally with vibration and oil debris data collected from fatigue tests performed in the NASA Glenn Spiral Bevel Gear Test Facility. Spiral bevel gears are used in helicopter transmissions to transfer power between nonparallel intersecting shafts.

Vibration data will be collected from accelerometers and used to calculate previously validated gear vibration diagnostic algorithms. Oil debris data will be collected using a commercially available in-line oil debris sensor. Oil debris and vibration data will be integrated using fuzzy logic and decision fusion analysis techniques. The goal of this research is to provide the end user with clear information on the health of the gears.

\section{Experimental Investigation}

Experimental data was recorded from tests performed in the Spiral Bevel Gear Test facility at NASA Glenn Research Center. A detailed analysis of this test facility can be found in the references [4], [5]. The Spiral Bevel Gear Test Facility is illustrated in Figure 1. The test rig is used to study the effects of gear material, gear tooth design, and lubrication on the fatigue strength of gears. The facility 


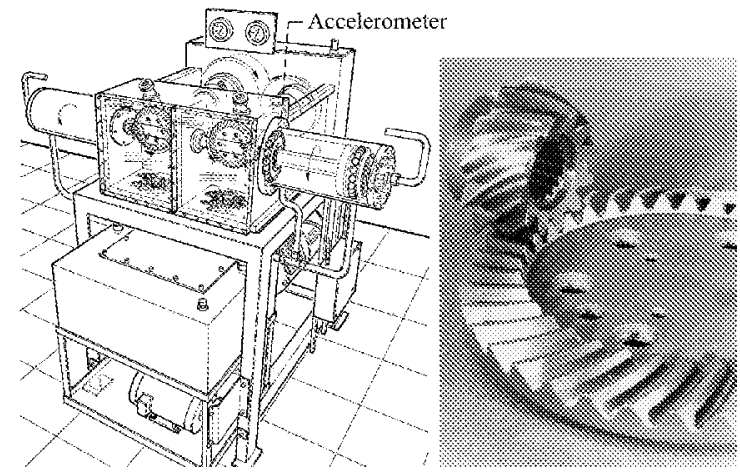

Figure 1. Spiral Bevel Gear Fatigue Rig.

uses a closed loop torque regenerative system. Two sets of spiral bevel gears can be tested simultaneously. Fatigue tests are performed on aerospace quality gears under controlled operating conditions. The 12 tooth pinion and 36 tooth gear have 5.14 in. $(13.06 \mathrm{~cm})$ diametral pitch, 35 degree spiral angle, 1 in. $(2.54 \mathrm{~cm})$ face width, 90 degree shaft angle, and 22.5 degree pressure angle. Tests are performed for a specified number of hours or until surface fatigue occurs.

The principal objective of this research is the detection of pitting damage on spiral bevel gears. Pitting is a fatigue failure that occurs when small pieces of material break off from the gear surface, producing pits on the contacting surfaces [6]. Gears are run until pitting occurs on one or more teeth. For the purpose of this work two levels of pitting are defined as initial pitting (pits less than $0.04 \mathrm{~cm}$ diameter and cover less than 25 percent of tooth contact area) and destructive pitting (pits greater than $0.04 \mathrm{~cm}$ diameter and cover greater than 25 percent of tooth contact area). If not detected in time, destructive pitting can lead to a catastrophic transmission failure if the gear teeth crack.

Data was collected once per minute. Shaft speed was measured by an optical sensor once per each gear shaft revolution. Torque was measured using a torque meter. Torque on the gear shaft during testing was on average 7500 in-lbs. Oil debris data was collected using a commercially available oil debris sensor that measures the change in a magnetic field caused by passage of a metal particle. The amplitude of the sensor output signal is proportional to the particle mass. The sensor counts the number of particles, their approximate size based on user defined particle size ranges, and calculates an accumulated mass [7]. For these experiments, 14 size ranges from 2251000 microns were defined.

Vibration data was measured by two accelerometers located on the left and right pinion shaft bearing housing. The location of the right accelerometer is shown in Figure 1. The location of the left accelerometer is at the same relative position on the left side of the gearbox. The accelerometers are lightweight, piezoelectric accelerometers. The left accelerometer measures primarily the vibration from the left pair of gears and the right accelerometer measures primarily the vibration from the right pair of meshing gears. The test pinion had 12 teeth with a shaft speed of 10,200 RPM and the gear had 36 teeth with a shaft speed of 3400 RPM. The meshing frequency was 2040 cycles/second. The shaft speed was measured on the test gear shaft. For every revolution of the test gear, there were three revolutions of the pinion. Vibration data was sampled at $100 \mathrm{KHz}$ for 2 seconds duration. Time synchronous averaging was performed from the raw vibration data for 113 revolutions of the test gear. The signal time-synchronous average is obtained by taking the average of the signal in the time domain with each record starting at the same point in the cycle as determined by the once per gear revolution tachometer signal [8]. The time synchronous average data was then used to calculate two vibration diagnostic parameters FM4 and NA4 Reset.

FM4 was developed to detect changes in the vibration pattern resulting from fatigue damage on a limited number of teeth [9]. The theory behind FM4 is that for a gear in good condition, the difference signal would be approximately random noise with a Gaussian amplitude distribution. The standard deviation should be relatively constant, and normalized kurtosis has a value of three. When a tooth develops a major defect, a peak or series of peaks appear in the difference signal, causing the kurtosis value to increase [8]. One problem with the FM4 parameter is that it decreases in sensitivity as the number of peaks of similar magnitude increase beyond two. For this reason, NA4 was developed for failures that involve more than two teeth.

NA4 was developed to detect the onset of fatigue damage and to continue to react to the damage as it spreads [10]. However, it does not perform well under fluctuating load conditions. NA4 Reset was developed from NA4 for applications with load fluctuations [11]. FM4, NA4 and NA4 Reset are dimensionless parameters with nominal values of approximately 3 . When gear damage occurs, the values of FM4 and NA4 Reset increase [12].

\section{Decision Fusion Analysis}

Multisensor data fusion analysis techniques were chosen to be applied to gear damage data collected from the two accelerometers and an oil debris sensor. Multisensor data fusion is a process similar to methods humans use to integrate data from multiple sources and senses to make decisions. In this process, data from multiple sensors are combined to perform inferences that are not possible from a single sensor. Commercially available software was used to perform the analysis [13].

Sensor data can be fused from the raw data level, feature level, or decision level. Decision level fusion was chosen to integrate these features because this does not limit the fusion process to a specific feature. By performing fusion at the decision level, new features can be added to 
the system or different features can be used without changing the entire analysis. This allows the most flexibility when applying this process to other condition based systems since, in most cases, different sensors and post-processing methods are used.

Features are extracted from the vibration and oil debris data for input into the data fusion system. Vibration algorithms FM4 and NA4 Reset are calculated for the two accelerometers, but only one feature for FM4 and NA4 Reset is input into the model. FM4 and NA4 Reset with the higher value is input into the model. The larger value of FM4 and NA4 was chosen to indicate the side with the most damage and to limit the features to 3 . A more complex model can be developed with additional features but is outside the scope of this paper. The accumulated mass measured is used as the feature for the oil debris sensor [14].

Fuzzy logic membership functions were defined for the identity declaration step. Fuzzy logic was chosen because it is tolerant of imprecise data, flexible and can incorporate the experience of experts. Fuzzy logic starts with a fuzzy set, extending boolean set theory to a continuous valued logic via the concept of membership functions valued between 0 and 1 . The truth of any statement becomes a matter of degree. The fuzzy logic membership functions identify the damage level on each feature. Levels of damage are indicated by the oil debris and vibration features oil debris mass, FM4, and NA4 Reset. Figure 2 shows the data fusion model used for this application.

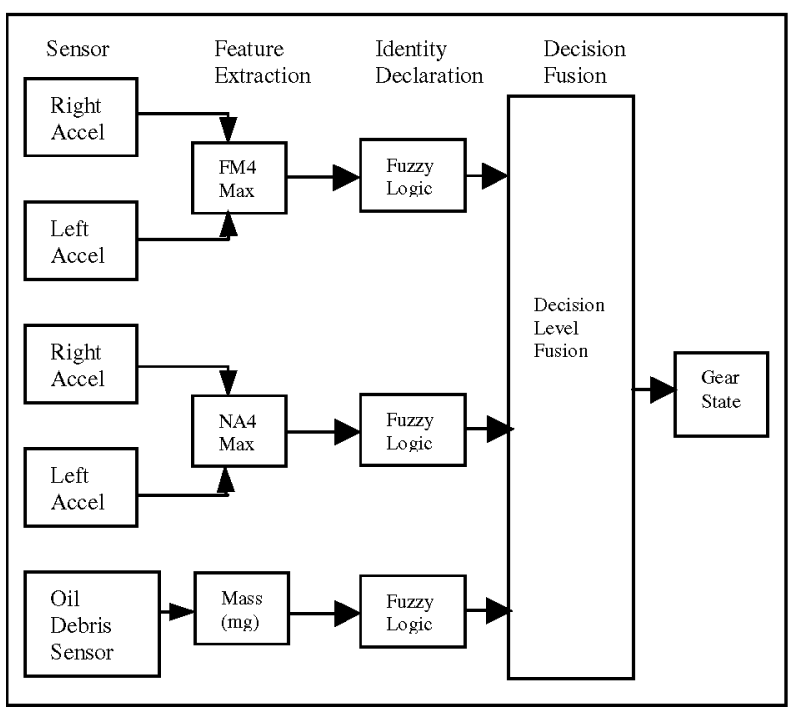

Figure 2. Decision Level Fusion Model.
Fuzzy logic is used to identify the damage level on each feature and to perform the decision level fusion process on the features. Although other data fusion techniques are available, fuzzy logic was chosen based on the results of several studies to compare production rules, fuzzy logic and neural nets. One study found fuzzy logic the most robust when monitoring transitional failure data on a gearbox [15]. Another study comparing automated reasoning techniques for condition-based maintenance found fuzzy logic more flexible than standard logic by making allowances for unanticipated behavior [16]. The fuzzy logic process consists of converting each piece of input data to degrees of membership, aggregating all outputs into a single fuzzy set, then converting fuzzy membership information into a single output.

Membership functions for the features are defined as levels of damage. Levels of damage are damage low (DL), damage medium (DM), and damage high (DH). The levels of damage for each feature are as follows: oil debris mass (DL, DM, DH), NA4 Reset (DL, DH), and FM4 (DL, DH). Membership functions and rules for the membership functions were developed based on analysis of this experimental data and the experience of the diagnostician. A detailed description of the process used to define the membership functions is referenced [17]. The membership functions and rules used for this analysis are shown in Table 1 and Figure 3. Triangular membership functions were used because of the ease of modifying the membership functions for other geared applications. The only parameters that need to be changed are the input/output scaling factors on the membership functions.

Table 1. Rules for Bevel Rig Data Fusion Model

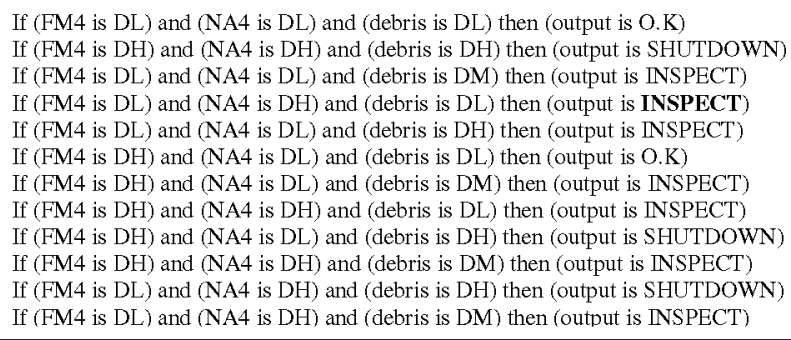

Decision level fusion is then performed integrating membership functions with fuzzy logic rules. The output is the state of the gear. The output of the system is defined as the state of the gear and possible action by the end user. The three states of the gear are O.K. (no gear damage), inspect (initial pitting), and shutdown due to damage (severe destructive pitting). 

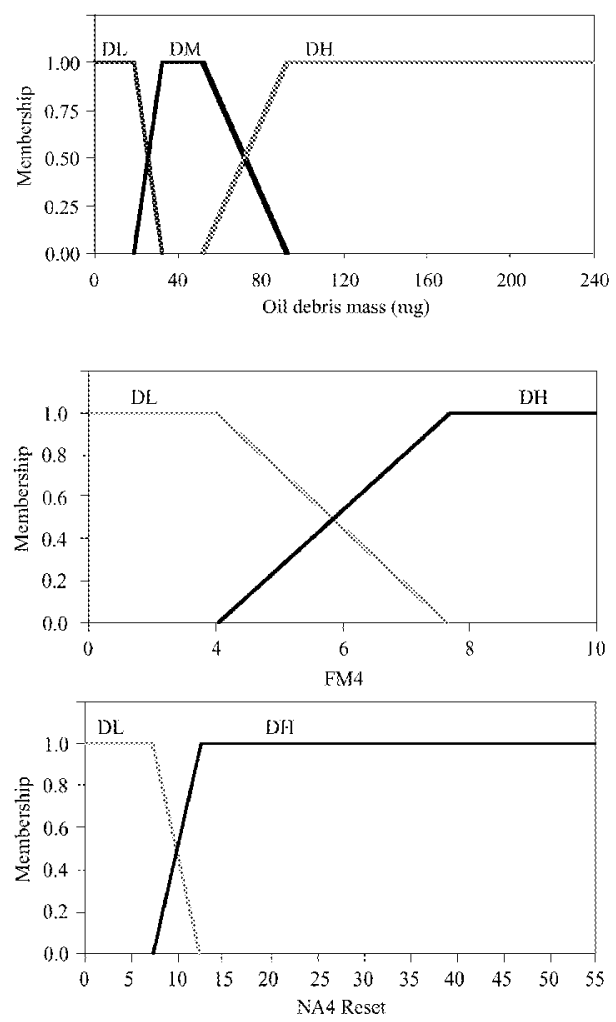

Figure 3. Feature Membership Functions.

\section{Discussion of Results}

The results discussed in this section are based on data collected during 6 experiments. During experiments 1 and 2 , only oil debris data was collected. And, during experiment 2, only the total debris at test completion was measured. At test completion of experiment 1, initial pitting was observed on one pinion tooth. At test completion of experiment 2, destructive pitting occurred on 2 teeth on the right pinion and initial pitting occurred on one tooth on the left pinion. This data was used to define the oil debris feature membership functions. Oil debris and vibration data was collected for experiments 3 through 6 and is discussed in the following paragraphs. The amount of debris measured at test completion for all 6 experiments is shown in Table 2.

Table 2. Debris at test completion.

\begin{tabular}{|c|c|c|}
\hline Experiment & Readings & Mass \\
\hline 1 & 29496 & 42 \\
\hline 2 & NA & 104.3 \\
\hline 3 & 1835 & 42.4 \\
\hline 4 & 6073 & 26.5 \\
\hline 5 & 10569 & 41.2 \\
\hline 6 & 4840 & 137.7 \\
\hline
\end{tabular}

The right side vibration features and oil debris features for experiment 3 are plotted on Figure 4. Although vibration data was collected on both sides of the gearbox, the vibration feature on the right side began to substantially increase during the test, indicating damage was beginning to occur on the right side of the test rig. The gears were inspected at test completion and damage to two teeth on the right side pinion is shown in Figure 4. Figure 4 also shows the output of the decision fusion model for this experiment. The output of the model indicates three states of the gear based on 3 shades of gray: O.K; inspect; and shutdown. The $\mathrm{x}$-axis, labeled reading number, is the same on both the feature plot and the output plot. The reading number is also the run time in minutes since data was collected once per minute. If the model was available on-line during testing, the gears would have been shutdown for inspection at approximately reading 1500 , since the output indicates to inspect the gears due to damage. If initial pitting was of interest to the end-user of the diagnostic tool, the oil debris membership function or rules could be adjusted to be more sensitive to this type of failure.
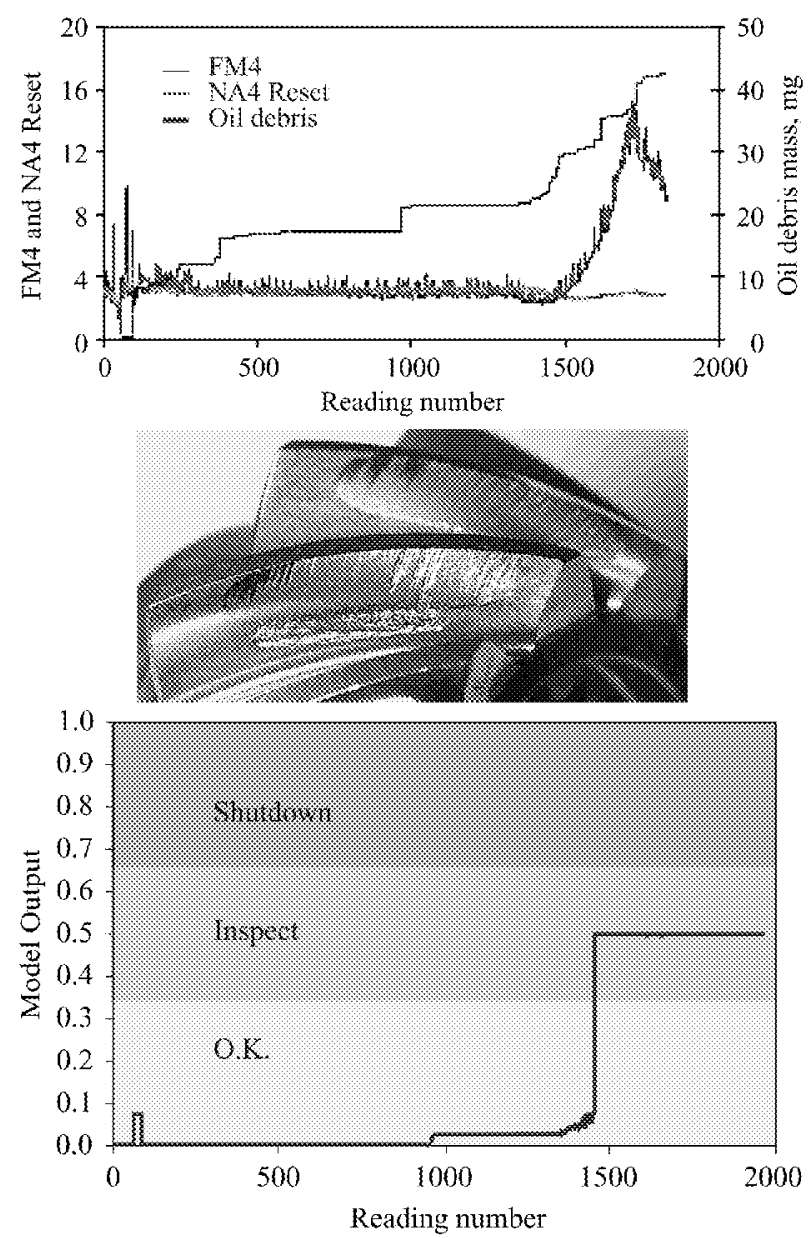

Figure 4. Vibration oil debris features and damage to right pinion teeth for bevel test 3 . 

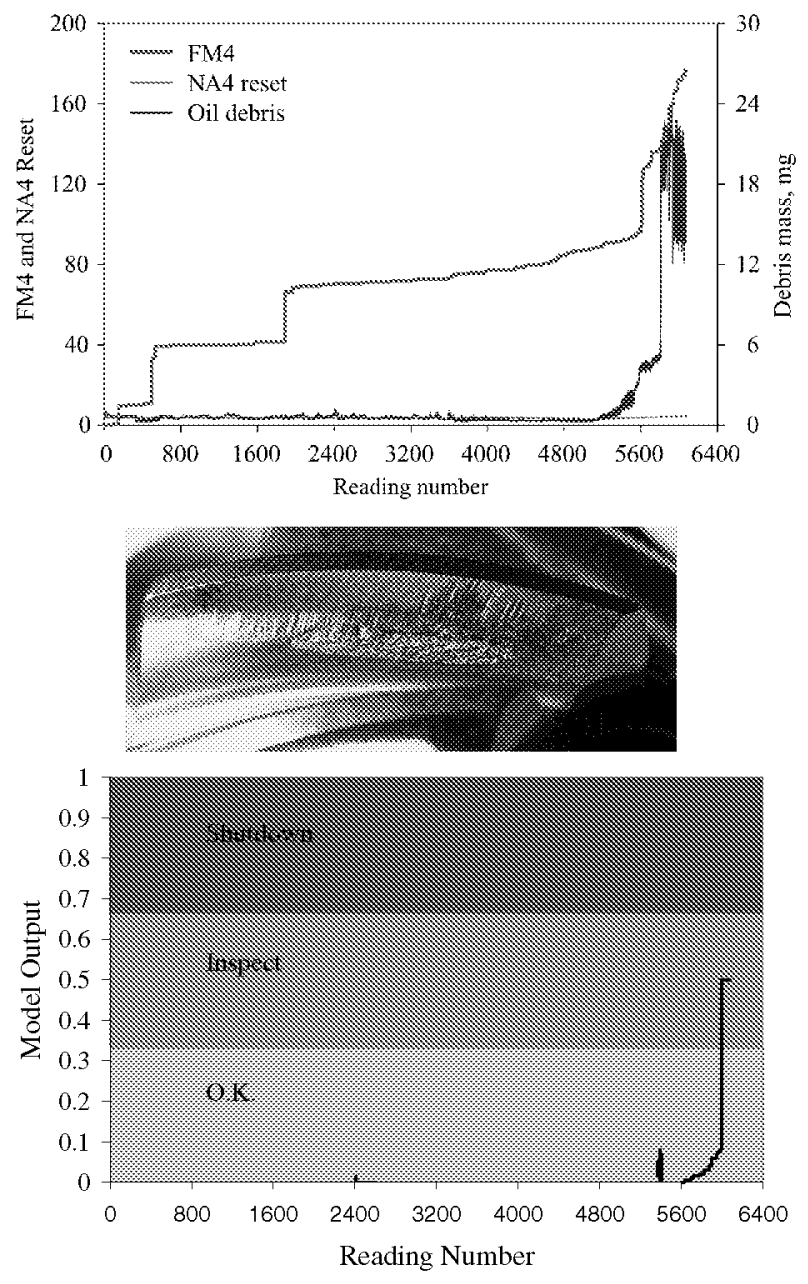

Figure 5. Vibration oil debris features and damage to left pinion teeth for bevel test 4 .

The left side vibration features and oil debris features for experiment 4 are plotted on Figure 5. For this experiment, the vibration feature calculated from the left accelerometer began to substantially increase indicating damage was beginning to occur to the gears on the left side of the test rig. The gears were inspected at reading 5742 and pitting began on one tooth on the left pinion. The gears were inspected at test completion and the damage to the one tooth on the left side pinion is shown in Figure 5. Figure 5 also shows the output of the decision fusion model for this experiment, indicating to inspect the rig due to damage.

The left side vibration features and oil debris features for experiment 5 are plotted on Figure 6 . For this experiment, the vibration feature calculated from the left accelerometer began to substantially increase indicating damage was beginning to occur to the gears on the left side of the test rig. The gears were inspected at test completion
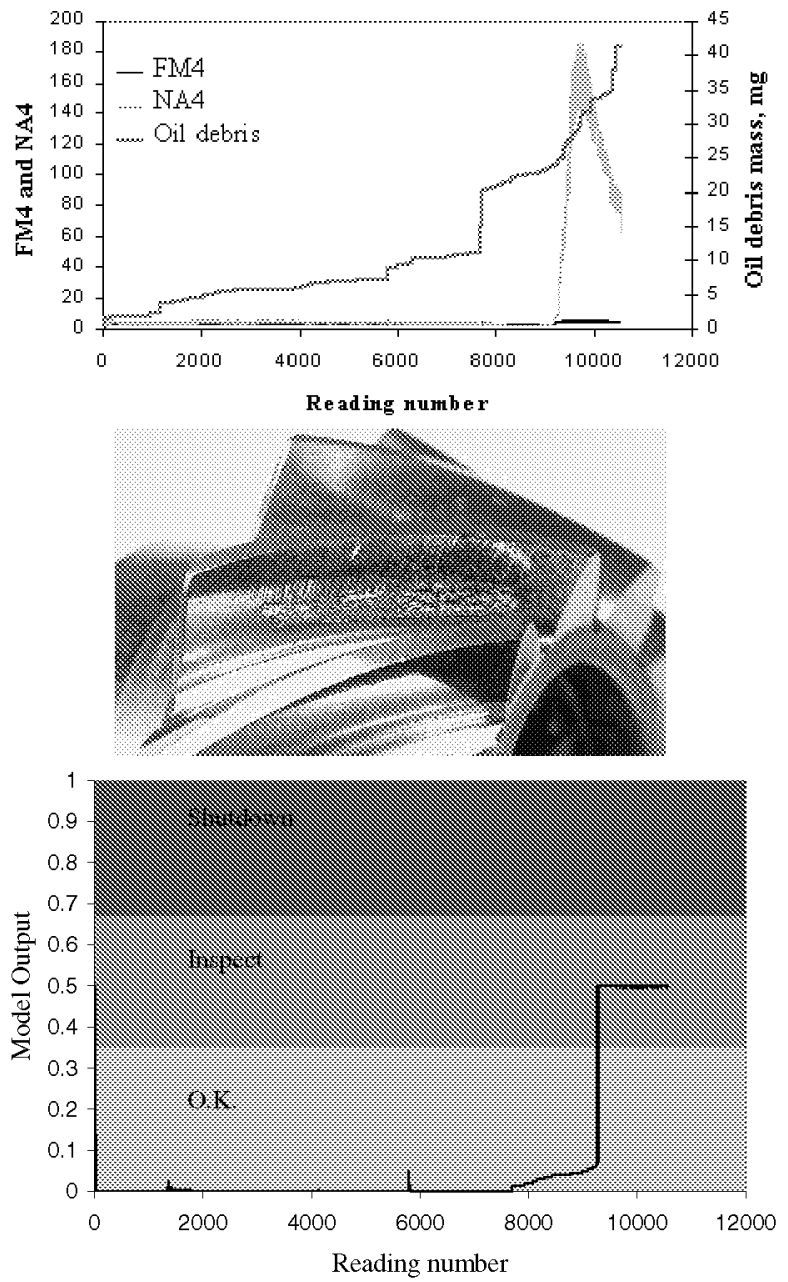

Figure 6. Vibration oil debris features and damage to left pinion teeth for bevel test 5 .

and damage to one tooth on the left side pinion is shown in Figure 6. Figure 6 also shows the output of the decision fusion model for this experiment. The output indicates to inspect the gears due to damage at approximately reading 9200.

The right side vibration features and oil debris features for experiment 6 are plotted on Figure 7. Although vibration data was collected on both sides of the gearbox, the vibration feature on the right side began to substantially increase early on in the test. The gears were inspected at reading 99 and initial pitting was beginning to occur on the right side of the test rig. Initial pitting was triggered by vibration algorithm NA4, since debris membership functions were not as sensitive to initial pitting. The gears were inspected at test completion and destructive pitting to one tooth on the right side pinion is shown in Figure 7 Figure 7 also shows the output of the decision fusion model for this experiment. Inspect was indicated early on in the 

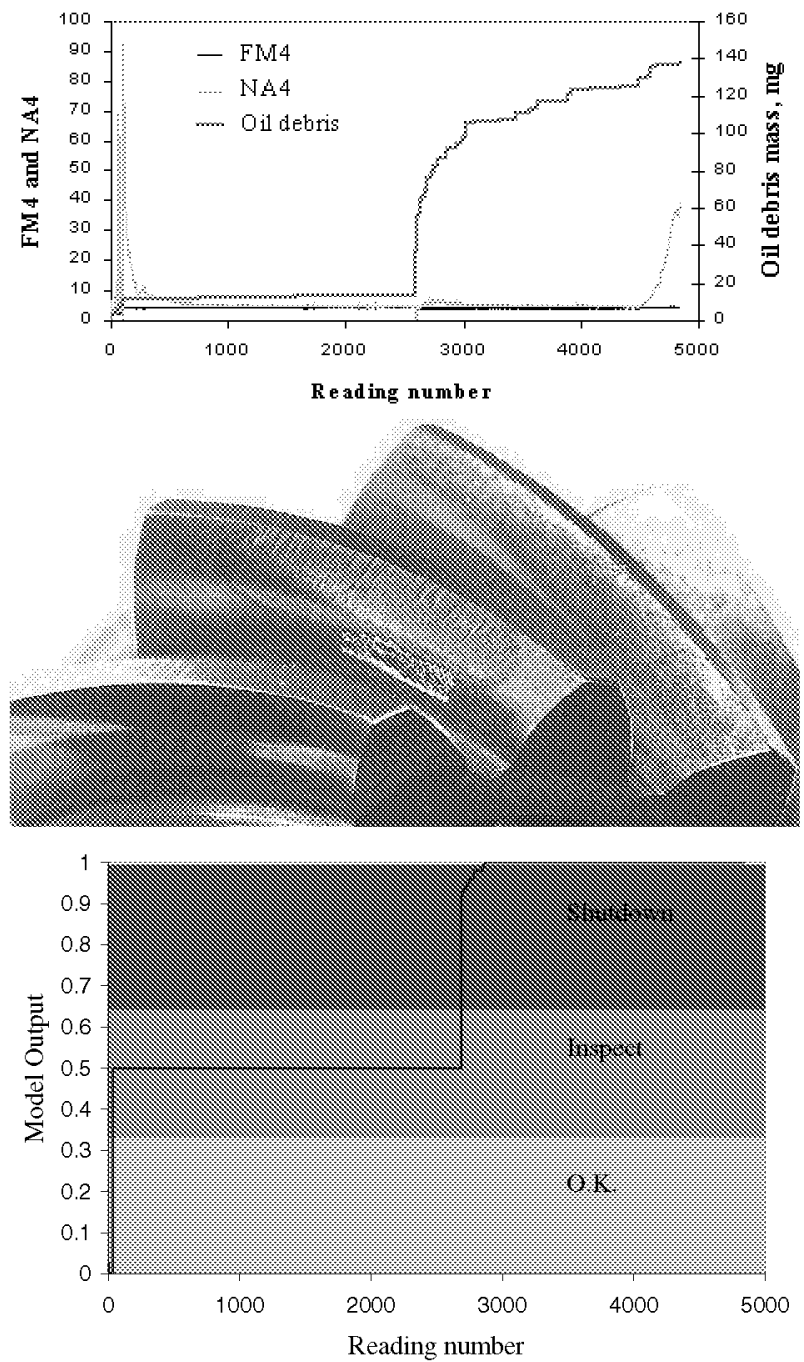

Figure 7. Vibration oil debris features and damage to right pinion teeth for bevel test 6 .

test and shutdown was indicated at approximately reading 2600. At test completion, it was found that damage also occurred on the pinion bearing. The damage is shown in Figure 8. Although the sensitivity of the parameter can be adjusted to be more sensitive to different levels of damage, the parameter must be defined on the type of failure the end user is trying to detect. The vibration features are specific to gear damage detection. Additional features and logic must be programmed into the model to differentiate between gear and bearing failures.

Additional vibration diagnostics for bearing damage detection can be added to the model to predict future failures. As more data is acquired on different types of

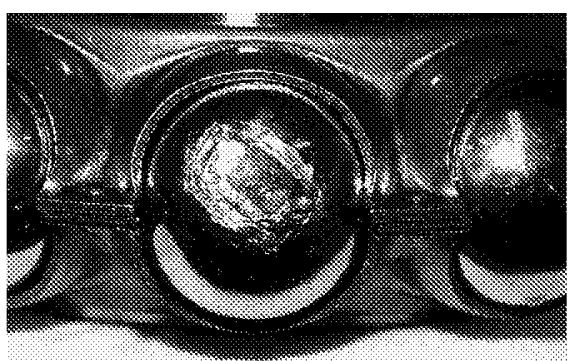

Figure 8. Damage to right pinion bearing for bevel test 6 .

failures, the model can be modified to recognize unanticipated failures. The bearing failure also reinforces the importance of fusing different measurement technologies for damage detection since each have strengths and weaknesses for different applications.

\section{Conclusions}

After review of the data from these experiments, the advantage of fusing the features of different measurement technologies is evident. The output gives clear information to the end user when making a decision based on the data. As a diagnostician, it is important to identify the end user of the diagnostic tool early on in the process. The end user of most helicopter transmission diagnostic tools is the technician that determines if maintenance is required on the transmission. If the tool being developed requires hours of analysis and large amounts of stored data to determine the health of the system, it is probably not feasible for this application. It is thus important to keep the man-machine interface in mind when designing diagnostic tools.

The model developed can incorporate the knowledge of the diagnostician into a system that can be used to make clear decisions on the status of the geared system relieving the end user of interpreting large amounts of sensor data. This research demonstrated integration of two measurement technologies, oil debris analysis and vibration, results in a system with improved damage detection and decision-making capabilities. Understanding the strengths, weaknesses and constraints of each measurement technology, then capitalizing on these strengths via data fusion, is key to the development of future health monitoring systems.

\section{References}

[1] Larder, B.D. (1999): Helicopter HUM/FDR: Benefits and Developments. Proceedings of the 55th AHS International Annual Forum, American Helicopter Society, Alexandria, VA. 
[2] Stewart, Ronald M.; and Ephraim, P. (1997): Advanced HUMS and Vehicle Management Systems Implemented Through an IMA Architecture. Annual Forum Proceedings of the American Helicopter Society, vol. 53/V2, pp. 1257-1266.

[3] Pouradier, Jean-Marc; and Trouvé, Michel (2001): An Assessment of Eurocopter Experience in HUMS Development and Support. Proceedings of the 57th AHS International Annual Forum, American Helicopter Society, Alexandria, VA.

[4] Handschuh, Robert F. (1995): Thermal Behavior of Spiral Bevel Gears. NASA TM-106518.

[5] Handschuh, Robert F. (2001): Testing of Face-Milled Spiral Bevel Gears at High-Speed and Load. NASA/TM-2001-210743.

[6] Townsend, Dennis P. (1991): Dudley's Gear Handbook. McGraw-Hill, New York, NY.

[7] Howe, B.; and Muir, D. (1998): In-Line Oil Debris Monitor (ODM) for Helicopter Gearbox Condition Assessment. AD-a347 503. Defense Technical Information Center, Ft. Belvoir, VA.

[8] Zakrajsek, James J. (1989): An Investigation of Gear Mesh Failure Prediction Techniques. NASA TM-102340.

[9] Stewart, R.M. (1977): Some Useful Data Analysis Techniques for Gearbox Diagnostics. Machine Health Monitoring Group Report MHM/R/10/77, University of Southampton.

[10] Zakrajsek, J.J.; Townsend, D.P.; and Decker, H.J. (1993): An Analysis of Gear Fault Detection Methods as Applied to Pitting Fatigue Failure Data. NASA TM-105950.
[11] Dempsey, Paula J.; and Zakrajsek, James J. (2001): Minimizing Load Effects on NA4 Gear Vibration Diagnostic Parameter. NASA/TM-2001-210671.

[12] Zakrajsek, James J.; Handschuh, R.F.; and Decker,H.J. (1994): Application of Fault Detection Techniques to Spiral Bevel Gear Fatigue Data. NASA TM-106467.

[13] Fuzzy Logic Toolbox for use with MATLAB® (1998): Mathworks, Inc., Natick, MA.

[14] Dempsey, Paula J. (2001): Gear Damage Detection Using Oil Debris Analysis. NASA/TM-2001210936.

[15] Hall, David L.; Garga, A.K.; and Stover, J. (1999): Machinery Fault Classification: The Case for a Hybrid Fuzzy Logic Approach. Society for Machinery Failure Prevention Technology, H.C. Pusey, S.C. Pusey, and W.R. Hobbs, eds., Haymarket, VA, pp. 241-252.

[16] McGonigal, Daniel Lewis (1997): A Comparison of Automated Reasoning Techniques for ConditionBased Maintenance. M.A. Thesis, Pennsylvania State Univ.

[17] Dempsey, Paula J. (2002): Integrating Oil Debris and Vibration Measurements for Intelligent Machine Health Monitoring. $\mathrm{PhD}$ Thesis, The University of Toledo. 


\section{REPORT DOCUMENTATION PAGE}

Public reporting burden for this collection of information is estimated to average 1 hour per response, including the time for reviewing instructions, searching existing data sources gathering and maintaining the data needed, and completing and reviewing the collection of information. Send comments regarding this burden estimate or any other aspect of this collection of information. including suggestions for reducing this burden, to Washington Headquarters Services. Directorate for Intormation Operations and Reports, 1215 Jefferson Davis Highway, Suite 1204, Arlington, VA 22202-4302, and to the Office of Management and Budget. Paperwork Peduction Project (0704-0188), Washington, DC 20503.

\begin{tabular}{|l|c|c|}
\hline i. AGENCY USE ONLY (Leave blank) & $\begin{array}{c}\text { 2. REPORT DATE } \\
\text { August } 2002\end{array}$ & $\begin{array}{c}\text { 3. REPORT TYPE AND DATES COVERED } \\
\text { Technical Memorandum }\end{array}$
\end{tabular}

\begin{tabular}{l|l} 
4. TITLE AND SUBTITLE & 5. FUNDING NUMBERS
\end{tabular}

Spiral Bevel Gear Damage Detection Using Decision Fusion Analysis

6. ALTHOR(S)

WU-728-30-10-00

Paula I. Dempsey, Robert F. Handschuh, and Abdollah A. Afjeh

$1 L 162211 \mathrm{~A} 47 \mathrm{~A}$

7. PERFORMING ORGANIZATION NAME(S) AND ADDRESS(ES)

National Aeronautics and Space Administration

John $\mathrm{H}$. Glenn Research Center at Lewis Field

Cleveland, Ohio 44135-3191

8. PEPFORMING ORGANIZATION

REPORT NUMBEF

E-13356

9. SPONSORING/MONITORING AGENCY NAME(S) AND ADDRESS(ES)

National Aeronautics and Space Administration

Washington. DC 20546-0001

and

U.S. Army Research Laboratory

Adelphi, Maryland 20783-1145

10. SPONSORING/MONITORING AGENCY REPORT NUMBER

NASA TM-2002-211814

ARL-TR-2744

11. SUPPLEMENTARY NOTES

Prepared for the Fifth International Conference on Information Fusion sponsored by the International Society of Information Fusion, Annapolis, Maryland, July 8-11, 2002. Paula J. Dempsey, NASA Glenn Research Center; Robert F.

Handschuh, U.S. Army Research Laboratory, NASA Glenn Research Center; Abdollah A. Afjeh, University of Toledo, Toledo, Ohio. Responsible person, Paula I. Dempsey, organization code 5950, 216-433-3398.

12a. DISTRIBUTION/AVAILABILITY STATEMENT

Unclassified - Unlimited

Subject Category: 01

Distribution: Nonstandard

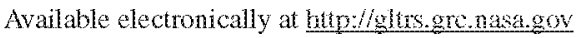

This publication is available from the NASA Center for AeroSpace Information, 301-621-0390.

13. ABSTRACT (Maximum 200 words)

A diagnostic tool for detecting damage to spiral bevel gears was developed. Two different monitoring technologies, oil debris analysis and vibration, were integrated using data fusion into a health monitoring system for detecting surface fatigue pitting damage on gears. This integrated system showed improved detection and decision-making capabilities as compared to using individual monitoring technologies. This diagnostic tool was evaluated by collecting vibration and oil debris data from fatigue tests performed in the NASA Glenn Spiral Bevel Gear Fatigue Rigs. Data was collected during experiments performed in this test rig when pitting damage occurred. Results show that combining the vibration and oil debris measurement technologies improves the detection of pitting damage on spiral bevel gears.

14. SUBJECT TERMS

15. NUMBER OF PAGES

Gears; Damage detection; Vibration; Wear debris; Data fusion; Fuzzy logic

13

17. SECURITY CLASSIFICATION OF REPORT

18. SECURITY CLASSIFICATION OF THIS PAGE

19. SECURITY CLASSIFICATION OF ABSTRACT

Unclassified

Unclassified

Unclassified

NSN 7540-01-280-5500

Standard Form 298 (Rev. 2-89)

Prescribed by ANSI Std. Z39-18

298-102 